\title{
Modifying Effects of Physical Processes on Starch and Dietary Fiber Content of Foodstuffs
}

\author{
Róbert Nagy $^{1}\left(\mathbb{D}\right.$, Endre Máthé ${ }^{1}$, János Csapó ${ }^{2,3}$ and Péter Sipos ${ }^{1, * \mathbb{C}}$ \\ 1 Faculty of Agricultural and Food Sciences and Environmental Management, Institute of Nutrition, \\ University of Debrecen, 138 Böszörményi Street, 4032 Debrecen, Hungary; nagy.robert@agr.unideb.hu (R.N.); \\ endre.mathe64@gmail.com (E.M.) \\ 2 Faculty of Agricultural and Food Sciences and Environmental Management, Institute of Food Technology, \\ University of Debrecen, 138 Böszörményi Street, 4032 Debrecen, Hungary; csapo.janos@gmail.hu \\ 3 Department of Food Science, Faculty of Miercurea Ciuc, SAPIENTIA Hungarian University of Transylvania, \\ Piata Libertatii 1, RO-4100, 530104 Miercurea Ciuc, Romania \\ * Correspondence: siposp@agr.unideb.hu
}

check for updates

Citation: Nagy, R.; Máthé, E.; Csapó, J.; Sipos, P. Modifying Effects of Physical Processes on Starch and Dietary Fiber Content of Foodstuffs. Processes 2021, 9, 17. https://dx.doi.org/ $10.3390 /$ pr9010017

Received: 9 November 2020 Accepted: 11 December 2020 Published: 23 December 2020

Publisher's Note: MDPI stays neutral with regard to jurisdictional claims in published maps and institutional affiliations.

Copyright: (c) 2020 by the authors. Licensee MDPI, Basel, Switzerland. This article is an open access article distributed under the terms and conditions of the Creative Commons Attribution (CC BY) license (https: / / creativecommons.org/ licenses/by/4.0/).

\begin{abstract}
Carbohydrates are one of the most important nutrients in human consumption. The digestible part of carbohydrates has a significant role in maintaining the energy status of the body and the non-digestible parts like dietary fibers have specific nutritional functions. One of the key issues of food processing is how to influence the technological and nutritional properties of carbohydrates to meet modern dietary requirements more effectively, considering particularly the trends in the behavior of people and food-related health issues. Physical processing methods have several advantages compared to the chemical methods, where chemical reagents, such as acids or enzymes, are used for the modification of components. Furthermore, in most cases, these is no need to apply them supplementarily in the technology, only a moderate modification of current technology can result in significant changes in dietary properties. This review summarizes the novel results about the nutritional and technological effects of physical food processing influencing the starch and dietary fiber content of plant-derived foodstuffs.
\end{abstract}

Keywords: dietary fibers; starch; physical food processing; technological properties of carbohydrates

\section{Introduction}

Carbohydrates produced by plants are a main energy source for all living organisms, though their bioavailability could feature some species-specific characteristics among animals and humans. In the context of human nutrition, carbohydrates can be rendered into digestible and non-digestible categories based upon the properties of carbohydrate utilization by the human digestive system. The non-digestible carbohydrates like dietary fibers on chemical grounds could be considered as three types: (i) non-starch type of polysaccharides like cellulose, hemicellulose, and arabinoxylan; (ii) non-digestible oligosaccharides, and (iii) resistant starch. Dietary fibers have an important role in the formation of the structure of foodstuffs, while their relevance in the prevention of numerous chronic diseases, such as type 1 or 2 diabetes, colon cancer, high blood pressure and cholesterol level, and different cardiovascular diseases has been demonstrated [1-4]. On the other hand, digestible carbohydrates, such as starch and its sugar monomers, provide energy, but also have a significant role in gel formation and water absorption and influence the viscosity, adhesion, and strength of binding amongst molecules. Starch is commonly used in several food processing technologies (e.g., in baking for crumb softening and as a food thickener and water binder), but other industries can also take advantage of its beneficial physical properties [5]. Starch does not swell in cold water, but forms a colloidal solution, gelatinizes when cooked, and retrogrades after cooling down, suggesting that such plausible modifications could widen its food-based technological range of application. 
It is noteworthy that the modifications of starch could influence its solubility, digestibility, and absorption, affecting its nutritional value. Moreover, certain physical and chemical treatments could inflict changes on the non-digestible carbohydrates, influencing their technological properties and nutritional values. The current review intends to summarize the physical processes specific to the food industry with respect to the modifications of starch and dietary fibers affecting their technological parameters, together with some nutritional considerations.

\section{Role of Carbohydrates in Nutrition and Food Processing}

Oversimplifying the nutritional importance of carbohydrates would emphasize their energy-providing role for animals and humans. Nevertheless, a more careful analysis would reveal a fairly versatile functional spectrum of carbohydrates, including the synthesis of fatty acids, amino acids, nucleotides, glycolipids, glycoproteins, and vitamins, affecting cellular metabolism, the cytoskeleton, and redox regulation. Based on the digestibility of starch, it can be classified into rapidly and slowly digestible starch categories (see Figure 1). The former's digestion to glucose is initiated in the buccal cavity, and it is completed in the upper portion of the small intestine. The slowly digestible starch is digested and absorbed gradually after ingestion in the intestinal tract, resulting in a slower and more even glucose absorption, playing an important role in regulating blood insulin level, which helps in treating type 1 and 2 diabetes, cardiovascular diseases, and obesity $[4,6]$.

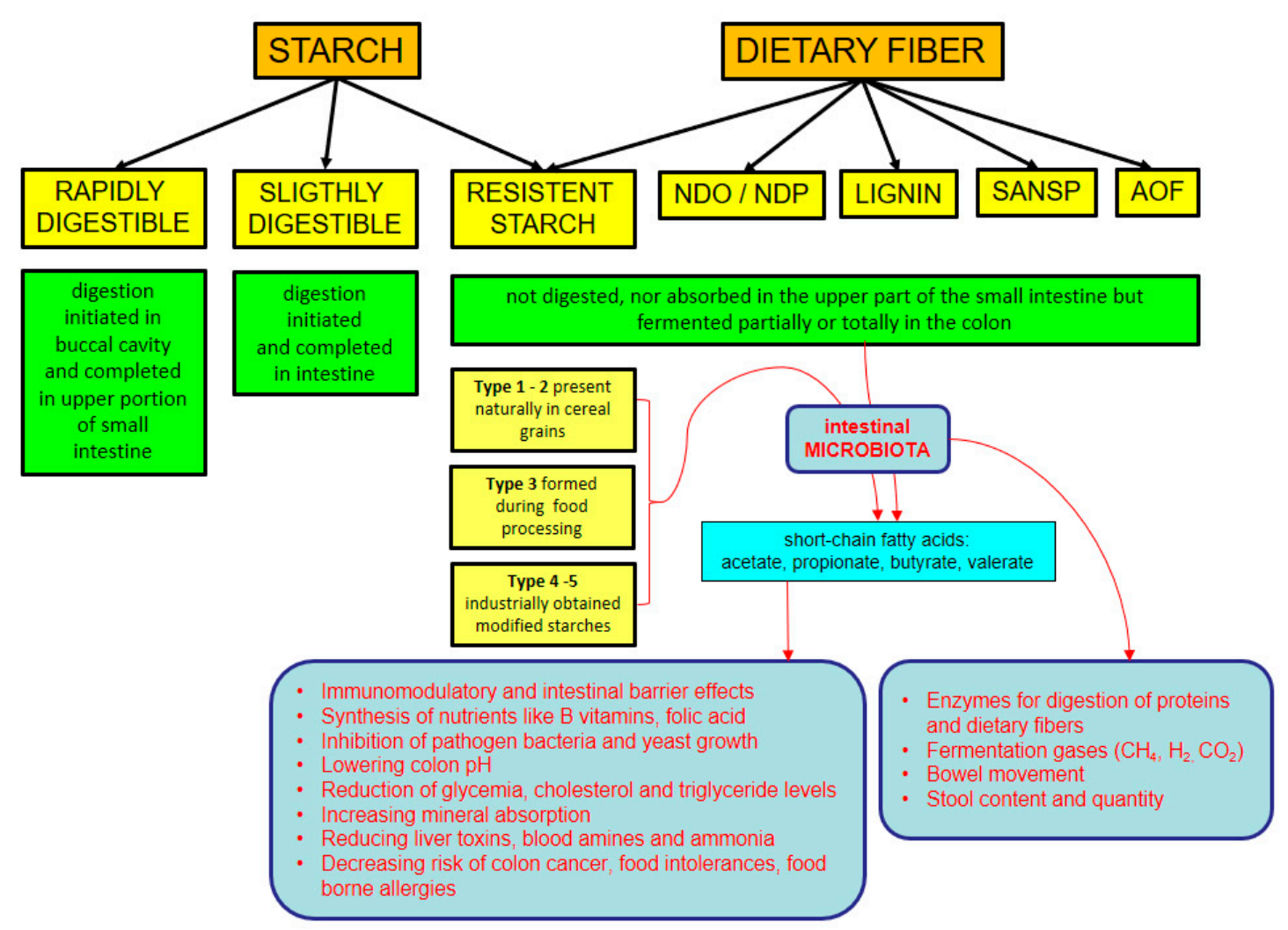

Figure 1. The comparison of some starch and dietary fiber-related properties. Note: NDO—non-digestible oligosaccharide; NDP—non-digestible polysaccharide (cellulose, hemicellulose, polyfructoses, gums, mucilages, pectins); SANSP— substances associated with non-starch polysaccharides (waxes, cutin, suberin); AOF-animal origin fiber (chitin, chitosan, chondroitin).

The third kind of starch is the so-called resistant type, which is neither digested nor absorbed in the upper part of the small intestine of healthy humans, therefore, it could be classified as dietary fiber. The resistant starch could be divided into five subgroups based on the origin of its resistance to digestion. Type 1 and 2 are present naturally in cereal grains, 
while type 3 is formed during food processing. Type 4 and 5 are industrially obtained modified starches that cannot be obtained naturally. The resistant starch passing through the human digestive tract without digestion and absorption is utilized by the gastrointestinal microbiota through fermentation, resulting in useful short-chain fatty acids such as propionic acid or butyric acid that play an important role in maintaining the health status. It was suggested that the digestive system of humans constantly faces mild inflammation, and the abovementioned microbiota produced fatty acids helping to reduce this inflammation, as well as the other chronic diseases associated with inflammation. In addition to its anti-inflammatory and antimicrobial effects against Salmonella typhimurium, propionic acid was suggested to increase insulin sensitivity $[4,7]$. Furthermore, the ingestion of resistant starch would reduce calorie intake, and therefore could exert a preventive role regarding excessive caloric intake, obesity, and metabolic syndrome, and might reduce the risk of colon cancer and high blood sugar level [4].

In contrast with starch, dietary fibers have been defined as plant-derived carbohydrates that are resistant to digestion and absorption in the human small intestine and reaching the colon would provide some health-promoting effects [8]. Carbohydrate-based dietary fibers of animal origin, like chitin, chitosan, and chondroitin, have also been identified, but collagen protein was also included in the dietary fiber category due to its physical properties.

Among the dietary fibers, the non-digestible oligosaccharides (NDOs) and polysaccharides (NDPs) are partially or completely fermented by the microbiome of the digestive apparatus of humans, and do play a major role in the regulation of technological and sensory parameters of foods, with some of them acting like mucus substances and gel-forming agents. The NDOs and NDPs are based on principal groupings like cellulose, hemicellulose, polyfructoses, pectins, gums, and mucilages. Most of the NDOs and NDPs are not or only slightly soluble in water, but they absorb a significant amount of water, hence, they could affect the structure of foods. In several cases, the incorporation of NDOs, like cyclodextrins, fructooligosaccharides, or galactooligosaccharides, and NDPs, like hemicellise, pectin, or beta-glucan, into recipes would positively modify texture, color, taste, viscosity, and the shelf life of foodstuff [2,9-12]. The fibers in question, besides their emulsifying properties, could absorb antioxidant compounds like phenolic compounds or vitamins, providing protection against the oxidation and rancidity of foods with a high fat content and increase product shelf life [12,13]. Moreover, such fibers could also bind different kinds of compounds, such as macronutrients, fat, and metal ions, and generate complex matrices within foodstuffs [12].

The dietary fibers exert a significant influence on the gastrointestinal tract, most particularly on the microbiome of the large intestine of humans, depending on a plethora of variables like their fermentation ability and dosage, together with the meal-specific matrix composition and structure [8]. Further to the concentration and composition of partially and/or highly fermentable dietary fibers present in the entire fiber-containing meal, and together with the consumer-specific physiological properties, the emerging physiological effects look rather complicated to study. Nevertheless, some physiological effects, like the absorption of nutrients, carbohydrate/fat, and sterol metabolisms, together with the colonic fermentation-related barrier and immune functions, and the production of stools, are intensively investigated in the case of healthy individuals and those with chronic diseases. The colonic microbiota produces enzymes to further assist the digestion of proteins, and to ferment dietary fibers, producing gases (methane, hydrogen, carbon dioxide), short chain fatty acids (SCFAs, C2-C5 organic acid-derived acetate, propionate, butyrate, valerate), and substantial amounts of lifeless bacterial mass that contributes to stool bulk. The extent of dietary fiber fermentation depends primarily upon its physicochemical nature, so that in the context of a cellulose-amylose-oat beta glucan-inulin-pea starch-potato starch comparison, increasing yields of acetate were observed, while the propionate and butyrate levels showed significant variation, and the valerate levels were mostly reduced [14]. Several studies are indicating the health-promoting effects of fermentable dietary fibers, 
though the mechanisms are still poorly understood [15]. The anticancer effect was suggested to be related to the decreased synthesis of carcinogenic substances by rebalancing the colon microbiome and reducing the number of pathogenic bacteria [16] and/or the anti-inflammatory and anti-apoptotic effects of colonic bacteria-derived metabolites [17]. The link between increased dietary fiber intake and decreased risk or alleviation of diabetes was attributed to well-fermented and viscous fibers that seemed to reduce the glycemic response and to increase insulin sensitivity. Several experimental datasets indicate that well-fermented and viscous dietary fibers derived from oats, psyllium, pectin, and guar gum can lower blood cholesterol levels and might play a role in reducing the risk of cardiovascular diseases. Other highly fermented fibers, like inulin and fructooligosaccharides, promote calcium, magnesium, and iron absorption in the colon, and are essential for the integrity of the intestinal barrier, preventing many gastrointestinal diseases.

It is worth mentioning that even poorly fermented dietary fibers can have healthpromoting effects since they could facilitate stool laxation by decreasing the colon-specific transition time, and they also bind substances such as bile acids and carcinogens, lowering the risk of colon cancer and cholesterol pathologies. Poorly or unfermented dietary fibers will slow down the absorption of other food components and could increase the feeling of satiety, making them suitable for anti-obesity diets $[10,18]$. Despite all the progress made in explaining the dietary fiber-specific health-associated effects, there is an urgent need for studies addressing their physical and technological properties to explain the relevant cause-effect type of correlations.

\section{The Modification of Carbohydrates and Their Properties}

Carbohydrates are one of the most common macronutrients of food, while the preferences of consumers seem to change with respect to high-sugar-containing foods. The consumption of bread, cakes, doughnuts and other flour products, and refined sugar-containing foods and drinks is declining, while the intake of whole grain cereals, legumes, and fruits, as well as candy, ice cream, and frozen yogurt increased in recent decades [19]. As the number of people who make health-conscious food choices is growing, the food industry has to find new processes to increase the health-promoting effects of newly developed foodstuffs. On the other hand, in several cases, the natural properties of carbohydrates do not meet the requirements of the production of a special product and, consequently, they need to be modified to provide better solubility for starch in cold water, slower retrogradation, or higher efficiency in releasing antioxidants from fibers. The range of gluten-free products must be diversified due to the increasing number of gluten allergies, and special lifestyle or diet trends of consumers, who seem to fully appreciate previously encountered taste, appearance, and other sensory and nutritional properties [20]. To give an example, wheat gluten has a unique property that makes it suitable to confer a unique stable structure to food products, which generally characterizes bakery and pasta products [21-23]. In the case of gluten-free products, fibers and other carbohydrates have to substitute for these functions that can be further improved by modifications to their properties [24-26]. The methods used for the modification of fibers and other carbohydrates depend on the nature and properties of such raw materials, paying attention to the anticipated effect. Generally, physical, chemical, and biological methods, and their various combinations, can be applied to reach the proposed quality parameters, like solubility, swelling properties, water- and oil-binding capacity, or free radical scavenging capacity $[5,10,12,25]$. Currently, the physical methods are of special interest to us as they are generally much faster than the chemical and microbiological ones, and do not make use of chemicals, which makes them safe and much more accepted by the consumers. In the current paper, we review the relevant physical processing methods used in food production that can have an effect on the nutritional properties of carbohydrates, increasing or decreasing their digestibility and influencing the technological behavior of starch and fiber (e.g., modifying solubility, swelling power, and structure-forming properties) (see Table 1). The general physical processes for these modifications are size reduction and heat and pressure treatment, but irradiation and the 
use of cold or non-thermal plasma for the modification of carbohydrate properties also seem to be often applied in manufacturing practice and have an influence on carbohydrate properties.

Table 1. Physical processing-induced nutritional modifications of carbohydrates.

\begin{tabular}{|c|c|c|}
\hline \multicolumn{2}{|c|}{ Physical Processes } & Effects on Carbohydrate Properties \\
\hline \multicolumn{2}{|c|}{ Size reduction } & Increase in fiber solubility [27] \\
\hline \multirow[t]{2}{*}{ Heat treatment } & $\begin{array}{c}\text { Superheating } \\
\text { Heat moisture treatment } \\
\text { Annealing } \\
\text { Drying }\end{array}$ & $\begin{array}{c}\text { Modified starch formation }[5,28,29] \\
\text { Starch damage [30] } \\
\text { Modification of resistant content formation } \\
{[25,31,32]} \\
\text { Starch complex formation }[30,33-35] \\
\text { Increase in fiber solubility }[36,37] \\
\text { Changes in the starch digestibility time }[29,38]\end{array}$ \\
\hline & Cooking, baking & $\begin{array}{l}\text { Increase in the starch digestibility time [39] } \\
\text { Change in glycemic index [39] }\end{array}$ \\
\hline \multirow{2}{*}{$\begin{array}{l}\text { Combined high } \\
\text { temperature and pressure } \\
\text { treatment }\end{array}$} & $\begin{array}{l}\text { High hydrostatic pressure, } \\
\text { autoclaving, steam explosion }\end{array}$ & $\begin{array}{c}\text { Changes in resistant starch content }[32,40] \\
\text { Fiber solubility increases [37] }\end{array}$ \\
\hline & Extrusion & $\begin{array}{l}\text { Increase in starch solubility [41] } \\
\text { Increase in resistant starch content }[32,42] \\
\text { Increase in fiber solubility }[1,43]\end{array}$ \\
\hline \multicolumn{2}{|c|}{ Cold plasma treatment } & Increase in resistant starch content [44-46] \\
\hline \multicolumn{2}{|c|}{ Radiation } & Changes in amylose-amylopectin ratios [47-49] \\
\hline
\end{tabular}

\subsection{Size Reduction}

Size reduction is a basic method for the processing of cereals and pulse grains. Based on particle size, different kinds of fractions can be separated into bran, shorts, and flour [50] and these fractions differ not only in size but composition and, therefore, in nutritional and techno-functional properties. Size influences water-binding capacity for both starch and fibers, due to an increase in surface area and pore volume upon grinding [51]. Milling also influences the amount of soluble fiber and arabinoxylan content. Zheng et al. found more than $10 \%$ arabinoxylan in hull-less bran, less than its shorts content of $50 \%$ and its flour content of one third. The result of size reduction depends on the applied method, and ball milling, rotor, impact and jet milling, cyclone milling, and roller milling have different effects on the properties of the milled product $[33,50]$. Craeyveld et al. evaluated dry ball milling and found a significant increase in water-extractable arabinoxylan oligomer content of pericarp-enriched wheat and rye bran as an effect of the increase in the jar volume capacity (from 16 to 50\%) and milling time (24 and $120 \mathrm{~h}$ ). On the other hand, yield showed a negative correlation to jar volume capacity [27]. Noort et al. compared rotor, impact, and jet milling in the decrease in average bran particle size from $831.1 \mu \mathrm{m}$ to $47.9 \mu \mathrm{m}$ for pure bran, while bran contained an aleurone layer from $205.6 \mu \mathrm{m}$ to $46.5 \mu \mathrm{m}$ and the different sized bran fractions were used for bread making. This size reduction strongly influenced water-binding capacity, as fibers bind water by capillary forces, which has a strong connection with the particle size. Water-binding capacity decreased from more than $500 \%$ to under $300 \%$ due to intensive milling [52]. The addition of a finely ground bran fraction to bread doughs and pasta results in a decrease in product size, darker color, and unfavorable sensory properties, and also makes the dough structure, baking, and pasting properties worse $[3,33,53,54]$. Coda et al. evaluated the effect of the fermentation of brans with different particle sizes $(750,400,150$, and $50 \mu \mathrm{m})$ by Lactobacillus brevis and Kazachastania exigua and found that a smaller than average particle size improves fermentation and the addition of carbohydrase enzyme further increased the effect [55]. 


\subsection{Heat Treatment}

Heat treatment is a widely used food processing application including several dry and wet techniques to reach goals like enzyme inactivation or roasting. The aforementioned techniques have benefits and disadvantages that must be carefully balanced with respect to the proposed goals. Dry heat treatment is found to be milder, but can result in drastic changes by increasing the temperature, while the wet heat treatment, performed in fluid or by steam, has a larger influence on chemical composition and, therefore, could influence the bioavailability of biologically active compounds [34]. The starch-related effects of the increased temperature are relatively well documented. By heating in the presence of water, starch undergoes a structural transformation and gelatinization, its crystal structure disintegrates, and its solubility, together with the rheological properties, are modified. With superheating, a dry high temperature will also produce modified starches that are soluble and swellable in cold water. On the other hand, using high pressure and wet heat treatments, the gelatinization parameters of starch could change, and it retains its original structure even at higher temperatures $[5,28]$. Chi et al. evaluated the combined effect of dry heating and annealing on corn and potato starches, and found that dry heat treatment resulted in shorter starch chains that were more prone to being rearranged into crystal structures during annealing. The combined application of these technological processes caused increased order in the structure of the double helix and in the crystal structure of starch, which influenced pasting properties and decreased digestibility [38]. Marston et al. evaluated the functional effects of dry heat treatments of $95^{\circ} \mathrm{C}$ and $125^{\circ} \mathrm{C}$ on sorghum flour, and observed promising results related on the volume and sensory properties of breads and cakes. These effects are due to the modified gelatinization properties of starch and increased ability to absorb water [38].

Drying has a special importance for pasta production, as the technological processing temperature strongly affects the properties of the product (fracture resistance, strength, elasticity, leaching losses) influenced by carbohydrate-protein and carbohydrate-carbohydrate reactions. Padalino et al. evaluated the effect of a drying temperature at $50{ }^{\circ} \mathrm{C}, 65^{\circ} \mathrm{C}, 75^{\circ} \mathrm{C}$, $80^{\circ} \mathrm{C}$, and $90^{\circ} \mathrm{C}$ on durum pasta, and observed better pasta properties as the temperature increased. The high drying temperature denatured proteins, partially gelatinized starch, and inactivated amylase enzymes, which reduced the amount of damaged starch in the doughs, as well as the amount of amylose, and resulted in less leaching into the cooking water. Furthermore, it also enhanced the formation of amylose-lipid complexes, and 90\% of the free lipids were in a bound form, which inhibited swelling and resulted in less sticky doughs. Denaturation of the proteins produced a structure reinforced with tighter S-S bridges, which inhibited starch swelling and amylose leaching. The only negative effect of the high temperature was the required cooking time that increased with the increase in drying heat [30]. Hot air drying also forms starch-protein complexes in the case of Chinese yam, influencing its functional properties, including solubility and swelling power, gelatinization parameters, pasting characteristics, and rheological properties [35]. Bucsella et al. also found that the combined dry and wet heat treatment helped to form protein-carbohydrate-lipid complexes, leading to increased water-soluble carbohydrate content, stronger dough structure, and increased dough development time [34].

Hydrothermal processing is one of the food manufacturing methods based on heat treatment, and the thermochemical conversion is based upon the heat-moisture treatment (HMT) or annealing that would yield more valuable food products. In the case of HMT, the applied moisture content is less than $35 \%$ and the temperature is between 80 and $140{ }^{\circ} \mathrm{C}$, while a higher moisture content (but less than $65 \%$ ) and lower, under gelatinization, temperature is typical for annealing. Annealing produces partial gelatinization and would increase the starting temperature of gelatinization up to $14{ }^{\circ} \mathrm{C}$ as compared to the native starch, because of the structural changes of granules and increasing amount of crystallized polymers. Besides gelatinization, the HMT influences crystallinity, recrystallization, enzymatic hydrolysis, and the freeze-thaw stability of starch. In the case of potato starch, decreased viscosity and pasting temperature were observed, while the breakdown viscosity 
diminished, showing higher resistance to heat and mechanical treatments. HMT also produced slower and less swelling [56,57]. In the case of banana starch, both treatments increased the pasting temperature, but the effects were much more significant for HMT $\left(12{ }^{\circ} \mathrm{C}\right)$ compared to annealing treatment $\left(1^{\circ} \mathrm{C}\right)$ [58]. The ratio of short sweet potato amylopectin chains was increased as a result of these treatments, and the kind of starch crystalline pattern was also modified from type 3 to type 1 [29]. In contrast, Hung et al. did not observe morphological changes in the HMT of unpolished rice, but found starch swelling and degradation to be inhibited, and the amount of resistant starch was also significantly increased $[25,31]$. The wheat bran hydrothermal treatments made a significant proportion of the arabinoxylan become water soluble, and improved the extraction of non-soluble fractions. A large fraction of fibers became soluble too: about $40 \%$ at $180{ }^{\circ} \mathrm{C}$ and $51 \%$ at $200{ }^{\circ} \mathrm{C}$ of hemicellulose and 10 and $15 \%$ of lignin, respectively [36].

Roasting and steaming are also performed at temperatures higher than $100{ }^{\circ} \mathrm{C}$, as for HMT. Their combined application of wheat bran improved the rheological properties when $30 \%$ was added to wheat flour. Combined with the untreated bran-flour mixture, increased water absorption capacity, better farinograph quality, and increased amylograph viscosity values were obtained, while the dough developmental time became longer. Lipase activity was also decreased, having favorable consequences in the terms of shelf life, and the formation of sterol-starch complexes was also observed $[29,59,60]$. Steam treatment also influenced the water soluble arabinoxylan, and decreased sugar content positively [37].

Powder drying leads to the fast evaporation of water from starch without influencing its structure, therefore, it has only a negligible effect on its properties [25]. However, freeze drying, the gentlest drying method, does affect the characteristics of starch. It has been found in several studies that the high pressure and low temperature could modify the starch structure, and induce amylopectin degradation, lower molecule weights both for amylose and amylopectin, shorter chains, a decreased proportion of amorphous phase, and an increased amount of double helices [35,61]. In the case of yam starch, the decreased solubility and swelling power were also evident [35]. Microwave heating is a relatively novel application and the generated direct and indirect effects on foodstuffs are strongly influenced by moisture content, since the microwaves can affect water molecules only. In the case of cereal carbohydrates, the use of microwave heating has been evaluated, and a treatment like $900 \mathrm{~W}$ for $2 \mathrm{~min}$ makes the wheat bran spread and generate a $0.3 \mathrm{~mm}$ layer with a slightly reduced water absorption capacity and dough stability when added into a $30 \%$ biscuit dough, though the time to dough formation was reduced. Peak viscosity was also improved compared to untreated bran, but not significantly [59]. The 5, 10, and 20 min long microwave treatments diminished the relative crystallinity of starch by 10.47, 6.42, and 2.91\% [62]. Microwave heating has also been combined with HMT for canna (Canna edulis Ker) starch, which increased the resistant starch content of starch from $27.7 \%$ to $55.5 \%$ and the amylose content from $12.5 \%$ to $18.5 \%$ [32]. Boiling and frying also can influence the carbohydrate content by decreasing the total carbohydrate content, while cooking increased the reducing sugar content by $9 \%$, and frying diminished it by $10 \%$ [39].

As is known, the physiological properties of starch are also influenced by high temperature, for example, baking leads to an increased resistant starch content, but the ratio of slowly digestible starch (SDS) to rapidly digestible starch (RDS) can also be affected by these modifications, and a higher SDS/RDS ratio seems to generate more beneficial physiological effects. The higher resistant starch content is also beneficial both for its physiological and technological effects, and, being classified as dietary fiber, this could influence the digestibility. Raw potatoes contain large amounts of resistant starch, which is significantly reduced during cooking and steaming, but higher amounts of RS can be measured after baking compared to other heat treatments due to the formation of amyloselipid complexes [39]. Microwave treatment also has an effect on resistant starch content. As a result of the treatment, a significant part of the starch is hydrolyzed, but resistant starch is also formed [4,39]. After boiling, steaming, and cooking under pressure, the total carbohydrate content of raw potatoes changed from $20 \%$ to $18.1 \%, 18.5 \%$, and $16 \%$, 
respectively, while microwave treatment increased it to $25.3 \%$ due to leaching and changes in water content [63]. However, Singh et al. reported a larger reduction of up to $40 \%$ in the case of potato starch after conventional cooking. Interestingly, the decrease in carbohydrate content has a positive effect on the glycemic index of raw materials, while the structural changes produced by cooking, steaming, and baking might positively influence the availability of starch to enzymes, so the glycemic index remains high in these processed foods. These methods also have a reducing effect on the proportion of amylose [39]. Annealing combined with drying caused a significant increase in SDS and a decrease in RDS, as well as a slight reduction of the resistant starch content. Similarly, the amount of SDS in corn increased from $2.08 \%$ to $9.98 \%$, compared to native corn starch, while the amount of resistant starch decreased from $5.44 \%$ to $3.94 \%$. Opposite effects were found in the case of potato starch: the amount of resistant starch increased significantly, from $5.68 \%$ to $10.7 \%$. The different features presented above could be also be caused by the structural differences of various plant-derived starch structures. The amount of RDS was reduced by $44 \%$ for both corn and potato starches. Based on these results, Chi et al. found that combined treatments could generate more significant effects on carbohydrates than just applying individual treatments alone [38]. HMT increased the resistant starch content of maize, lentils, and peas by $7.7,10.4$, and $11.2 \%$, respectively, compared to the values of untreated raw materials, which was further increased by the use of annealing. In other studies, a significant increase in the resistant starch content for waxy corn, rice, and potato starch was reported by the use of HMT, while starches from other raw materials showed opposing trends [32]. The amount of SDS in sweet potato starch increased threefold compared to native starch as a result of HMT treatment [29]. As a result of cooking, the digestibility and glycemic index of such starches were modified. Cooking in boiling water can alter the gelatinization of starch granules, and will increase the efficiency of digestive enzymes [39].

Heat treatments affect not only the starch but also dietary fibers, such as arabinoxylans and $\beta$-glucans, and the effect is more significant when heat treatment is performed under high pressure. Steiner et al. applied hydrothermal treatment to solubilize these components and split long chains. For this, brewer's spent grain was treated hydrothermally at 160 to $240{ }^{\circ} \mathrm{C}, 150 \mathrm{bar}$, for 2,5 , and $10 \mathrm{~min}$. The applied treatment did not produce any changes to cellulose, as was seen for a higher temperature like $300-330{ }^{\circ} \mathrm{C}$, but it significantly affected the length of the chains in the case of the arabinoxylans and glucans. The average molecular weight of untreated $\beta$-glucans was $248 \mathrm{kDa}$, which decreased to 179,29 , and $16 \mathrm{kDa}$ after $2 \mathrm{~min}$ of treatment, while the $\beta$-glucan content was decomposed totally above $200{ }^{\circ} \mathrm{C}$. Similar changes were found for arabinoxylan, but at higher $\left(180-220^{\circ} \mathrm{C}\right)$ temperatures. Hemicellulose was also affected by this hydrothermal treatment, $90 \%$ of which was decomposed to poly- and oligosaccharides. Additionally, a slight $\mathrm{pH}$ decrease was observed in the case of $\beta$-glucans, while for arabinoxylans, the $\mathrm{pH}$ decreased to 4.3 , inducing the formation of organic acids such as formic acid and levulinic acid [64]. Dry and wet heat treatments also affected the dietary fiber content of whole grain flours, so the amount of arabinoxylan fell, but the soluble dietary fiber content increased [34].

\subsection{High Pressure and Its Combination with Heat Treatment}

The use of high pressure generated a novel processing technology for the food industry, and it is based on high hydrostatic pressure (HHP) or high-pressure steam. In the case of HHP application, a canned or vacuum packaged product is placed in water under high, 10-1200 MPa, pressure which induces molecular changes in the product. Starch is partially gelatinized, and its enzymatic availability, together with digestibility, fall [32]. In such process, starch is partially dehydrated, followed by irreversible crystal structure decomposition and granule disintegration. Starch with high amylopectin content is more sensitive to such a treatment compared to starch rich in amylose [62]. On the other hand, type A starch with its compact structure is more sensitive than type B, which is mostly due to its looser structure, and as such, the technological process can induce structural changes. Duration, temperature, starch properties, and moisture content are the main properties 
influenced by the treatment $[62,65]$. Colussi et al. applied HPP alone and combined with HMT to potato starch, and they found that HMT alone decreased starch viscosity, while the combination of processes had an opposing effect. Their explanation for this phenomenon invoked the pressure-induced release and higher water absorption capacity of starch. The combined application of processes also increased breakdown viscosity, and therefore increased the stability of starch [57]. Others have found that HHP decreased the swelling power and viscosity [66]. While HMT promotes the formation of bonds between amylose and amylopectin, and increased pasting temperature, HPP has a reverse effect by limiting the swelling power and decreasing viscosity [57,67]. HHP increased the temperature of thermal transition, indicating that crystals with lower melting points are more sensitive, and decreased the relative crystallization, therefore, less energy was needed for gelatinization [57]. Liu et al. confirmed these findings on sorghum starch too. High pressure also influenced the formation of resistant starch as the highest generated amount was observed between 100 and $600 \mathrm{MPa}$, and a tenfold increase was observed for both wheat and quinoa, but starches with low amylose content would produce less resistant starch. Such an effect strongly depends on the duration of treatment, especially at lower pressures [32,40].

The second type of high-pressure treatment, also called steam explosion, consists of cycles of alternating action and inaction that exert an explosion-like effect on the substances. Interestingly, a threefold increase was observed for both the amount of water-extractable arabinoxylan and the reduced sugar as a consequence of applying steam explosion on fine milled wheat bran besides augmenting the efficiency of enzymatic hydrolysis [37].

Autoclaving, which combines high temperature and pressure, is a widely used processing method, especially for sterilization, but could also modify the technological and nutritional properties of the autoclaved foodstuff too. Structural changes in carbohydrates were induced by the application of combined high temperature and pressure treatments in chickpeas, and the amount of degradable sugars decreased, while the content of dietary fiber increased [68]. Autoclaving also has a significant effect on the structure of starch, since during the technological process, it begins to gelatinize, then rapidly matures, with the amylose chains being rearranged to form tight double helices with hydrogen bonds. As a result of this process, type 3 resistant starch is produced. This process is achieved though repeated cycles of autoclaving at $120-145^{\circ} \mathrm{C}$ for 5 to $30 \mathrm{~s}$ and resting that, when performed for several cycles, will induce multiple retrogradation in the starch [32].

\subsection{Extrusion}

Extrusion is a complex technological process, in which raw material with a high moisture content is subjected to high pressures, temperatures, and shear forces. The process and the resulting special porous structure of the final product are based on the structural transformation of starch, but fibers also play an important role in determining the properties of extruded products $[1,43]$. During the process, the steam released by the sudden pressure change leads to a sudden increase in the porosity and size of the raw material, while high temperature causes starch gelatinization, the loss of crystal structure, and the formation of new crosslinks between starch and proteins [41]. The extrusion of corn starch in the $50-85{ }^{\circ} \mathrm{C}$ temperature range has a particularly beneficial effect on the swelling power and water solubility of starch. The swelling power is slightly improved by $1-2 \%$, while the solubility is significantly increased by up to $15 \%$ as a result of extrusion, and the product shows significantly improved thermodynamic stability, while the gelatinization temperature could be increased from 66 to $91^{\circ} \mathrm{C}$. These phenomena can be explained by the high degree of gelatinization during extrusion and the subsequent change-induced structural rearrangement [41]. Liu et al. studied the effect of extrusion on the shortand long-term aging of rice starch using low temperature and transport speed but a longer extruder tube than is typical. During short-term retrogradation, the amylose shows rearrangement and recrystallization, while the long-term retrogradation caused the same result for amylopectin. Extrusion leads to a higher rate of degradation and damage of 
amylopectin than of amylose, because of its shorter chain length. Therefore, it can be used for long-term storage of products high in or exclusively containing amylose-derived starches [69].

During extrusion, raw materials are also subjected to strong shear forces, which also affect the properties of starch. Gelatinized starch shows shear thinning behavior, and continuous shear stress usually decreases the viscosity of both native and modified starches [70]. However, shear force can result in shear thickening actions in the case of different kinds of starch gels. Fang et al. experienced this shear thickening behavior in the case of waxy potato and waxy corn starch in a $10 \%$ dispersion at a $20 \mathrm{~s}^{-1}$ shear rate, but no such events were detected in the case of waxy rice starch gel. Similar effects could be observed in the case of gelatinized potato specific amylopectin, suggesting that the shear forces might induce intermolecular double helices, which were responsible for this outcome [71].

During the extrusion of corn flour, Bailoni et al. observed an increase in the amount of resistant starch from $0.7 \%$ to $5.1 \%$, while no change was experienced for oats and rye. Examining mango starch, the extrusion increased the initial resistant starch content to $9.7 \%$, while in combination with acid hydrolysis for corn starch, the amount of resistant starch increased from $11 \%$ to $20 \%$ [32,42].

Fibers, and especially the water-insoluble fraction, do affect negatively the extrusion and the quality parameters of a product, as they interact with starch and break down the structure formed by the starch. They also cause inhomogeneity in the structure because of their large size and reduce the amount of water available in the system, which prevents the starch from gelatinizing and also deteriorates its structural function [1,43]. To eliminate this problem, several technologies and the parameters of extrusion have been analyzed. When the different rates of material transport, moisture content, and temperature were evaluated based on the effect of fiber components in the extruded products, the rate of transport was found to be the most critical. The water-binding capacity of fibers decreased to $254-293 \%$ from the $361.9 \%$ value of the non-extruded wheat bran, but the proportion of soluble fibers increased by more than twofold from $2.3 \%$, which contributes ultimately to the improvement of sensory and physiological characteristics of extruded wheat products $[1,43]$. Because of such effects during the process, extrusion can also be used as a preparing operation before other treatments, for example, to damage the structure and cell walls of plant cells from raw materials, which provides better access for further enzymatic treatments. The extrusion of soybean okara and other soybean by-products allowed 95\% of cellulose to be hydrolyzed, while other acidic or alkaline treatments resulted in only $69 \%$ to $93 \%$ yields of hydrolysis [72].

\subsection{Atmospheric and Cold Plasma}

The use of cold or nonthermal plasma shows promising outcomes in enzyme inactivation, microbiological preservation, and starch modification. Cold plasma is a result of the atmospheric dielectric discharge, which causes the ionized gas to contain metastable atoms and molecules, such as $\mathrm{O} \bullet-$ and $\mathrm{OH} \bullet$, with a nearly zero net electrical charge [73]. Zhou et al. have found that atmospheric plasma treatment leads to lower gelatinization temperature and diminished relative crystallinity of normal and waxy corn starches [74]. Thirumdas et al. evaluated the cold plasma-generated effects on rice starch, and observed an elevated amylose content, while the gel hydration properties and syneresis study showed the intensification of amylose leaching, and other studies indicated the increase in pasting and final viscosities, together with the reduction of retrogradation tendency. Contrary to the former observations, Okyere et al. found the final viscosity values to drop after the treatment of waxy potato, corn, and rice starches, indicating that the effect of cold plasma treatment is largely dependent on the origin of the starch $[44,75,76]$. Han et al. found that the depolymerization of amylopectin and amylose, together with the cleavage of the side chains, had occurred, which caused the low weight fractions to increase from $0 \%$ to $53.4 \%$ in corn starch. In contrast, the amount of the high weight fraction increased due to the crosslinking of the smaller fractions in potato starch. In rice starch, the effect 
was influenced by the strength of plasma. The amorphous part of starch is more sensitive to the treatment because of its looser texture, and the B type of starch showed larger deformations than type A [62]. The plasma types could generate differentiated effects, like helium plasma inducing visible damage to starch particles, while nitrogen plasma had no such effect. The viscosity of plasma-treated corn and tapioca starch increased [77]. Okyere et al. observed that cold plasma treatment of rice, corn, and potato waxy starches improved the resistant starch content of corn and potato, but in the case of rice, a previous $\mathrm{CO}_{2}$ gas treatment was required to generate similar outcomes. The growing content of resistant starch in wheat flour, and in normal corn starch, was attributed to cold plasma treatments [44-46]. Having seen the multiple starch-related effects, the cold or nonthermal plasma technology emerges as a promising tool to modify flour functionality [78] and nutritional values [79], though the putative modifications of dietary fibers with such a technological process remain largely unknown.

\subsection{Radiation}

The evaluation of different irradiation processes on the carbohydrate properties is a novel field of food-related research, while their effects on food safety and quality are relatively well known.

Gamma radiation uses radiation from high-energy radioactive isotopes, such as ${ }^{60} \mathrm{Co}$ and ${ }^{137} \mathrm{Ce}$, which generate free radicals, and promote structural changes like breaking crosslinks or forming new chemical bonds. Polesi et al. applied $2 \mathrm{kGy}$ irradiation to the starch of two rice varieties. One of the varieties showed a decrease in the amount of short chains, and an increase in longer (with more than 24 degrees of polymerization) chains was evident, while the other rice variety-specific starch showed a totally reversed result. Radiation also affects the relative crystallinity and degradation of amorphous crystalline parts, being influenced by radiation intensity. Below $7 \mathrm{kGy}$, the amorphous, and from $9 \mathrm{kGy}$, the crystalline parts, are more sensitive to gamma radiation [62,80]. When corn starches with different amylose-amylopectin ratios were radiated with 1, 5, 10,25 , and $50 \mathrm{kGy}$, the amylose-like fraction in waxy corn starch was increased at $10 \mathrm{kGy}$, while higher doses, up to $50 \mathrm{kGy}$, caused a reduction of amylose content. Samples with low amylose content lose their pasting ability at high doses of irradiation, so the waxy corn starch looks more affected by the treatment with respect to its pasting properties, gelatinization temperatures, and relative crystallinity, indicating that amylopectin shows increased sensitivity towards gamma irradiation [47]. Similar changes (decrease in apparent amylose content, gelatinization consistency, swelling power, viscosity) in wheat and potato starches were also reported, and the potato starch was found to be more sensitive to sheardependent changes [48]. The ionizing radiation-induced changes are quite similar for other kinds of starches (e.g., tapioca, elephant foot yam, or bean) [49].

Microwave radiation is a non-ionizing radiation, which can increase temperature and cause fast changes in the affected material. Its effect of increasing the gelatinization temperature and decreasing the solubility and crystallinity were reported both for normal corn and wheat starch, but no influence was found on waxy corn starch, meaning that the previously mentioned effects are greatly dependent on amylopectin [81]. Shen et al. found similar, but greater, changes in the double helical structure and the crystallinity of potato starch induced upon microwave treatment as compared to modifications related to conventional heating. Corn flours treated with $400 \mathrm{~W}$ microwave radiation showed a higher level of V-type crystalline structure, indicating the formation of amylose-lipid complexes. Shorter $(0.5$ and $1 \mathrm{~min})$ treatments resulted in a higher peak viscosity compared to the untreated corn starch, but longer ( 3 and $4 \mathrm{~min}$ ) treatments resulted in lower values, showing an increase with the duration of microwave treatment in shear stability $[82,83]$.

Another kind of radiation applied in the food industry is the UV radiation, which has been used to control insects or spices, but can induce chemical changes too. It is a well-documented fact that UV radiation can modify starches by depolymerizing them. This kind of radiation breaks the bonds at 1-6 positions, thus shortening starch chains, and 
debranching the amylopectin. Amylopectin requires a higher energy level of UV radiation to make it break. This method successfully altered the physicochemical properties of starch in the way that the smaller molecular weight and lower crystallinity of starch were obtained [84]. Another study mentioned that UV radiation caused free radicals that induced crosslinking and depolymerization, and moreover, the formation of starch-derived dextrins was also facilitated [85]. Bajer et al. [86] evaluated the effect of UV radiation on starch from normal and waxy corn, wheat, and potato, and found that the chemical structure was not affected, suggesting a relatively substantial photostability, while starches lost the absorbed water and decreased the crystallinity property. Potato starch showed a lower level of photostability. The UV-B radiation degraded amylose, while UV-C decreased both amylose and amylopectin in cassava starch right after a pre-treatment with lactic acid and followed by UV irradiation [87], and the obtained flour showed higher baking expansion [88]. Exposure of durum wheat bran to UV radiation for $48 \mathrm{~h}$ showed a $25 \%$ decrease in the ferulic acid content of bran, and a $44 \%$ decrease in dehydrodiferulic acid content, which binds to dietary fibers, just like arabinoxylan. UV radiation also reduced the solubility of fibers by forming new crosslinks between the arabinoxylans. The extensibility of bran was reduced by $54 \%$, but the strength of the stress required to break it was increased by $30 \%$ when exposed to UV radiation [67].

\section{Conclusions}

The growing knowledge on the physical and chemical properties of carbohydrates continuously brings newer and newer information about this staple nutrient and the changing demands of consumers. Therefore, the need for the application of new technological processes in the food industry for both the development of new products and the improvement of nutritional, technological, and sensory properties of foodstuffs is an obvious priority. Physical methods (size reduction, heat treatment, high pressure and its combination with heat treatment, extrusion, atmospheric and cold plasma, radiation) are favored in several situations as they are easy to apply, toxicologically safer, more accepted than chemical methods, relatively inexpensive, and there are several nutritional aims that can be reached through their application. Despite all the progress seen in this field, several explanations are still missing, especially when it comes to the mechanisms of action and their effects on rheological and nutritional properties of the newly developed foodstuff.

The presented physical food processing methods can modify the structure, quantity, and digestibility of amylose/amylopectin, and could inflict changes upon the quantity and quality of dietary fiber. Furthermore, the abovementioned modifications could alter the ratios of macronutrients, most likely on the side of carbohydrate components, including the non-starch polysaccharides. It is also evident that through physical interventions, the resistant starch and dietary fiber proportions could be significantly increased, considering that such food components have beneficial effects on the human digestive and acquired immune systems. Through the synthesis of short-chain fatty acids, resistant starch helps maintain colon function, regulates colonocyte gene expression, cell cycle, and apoptosis. Increased SCFA production lowers colonic $\mathrm{pH}$ and stimulates bile acid secretion, and inhibits the conversion of primary and secondary bile acids, which is beneficial because secondary bile acids are cytotoxic to colon cells. Therefore, the food processing-related physical methods can directly affect the physicochemical properties of foods, while through the resistant starch and dietary fiber content, they can positively influence the blood sugar level, the insulin response, prevent colorectal cancer, etc. $[17,89,90]$. Future efforts should be directed to the comparative analysis of foodstuff-specific macro- and micronutrients in addition to dietary fibers and phytonutrient profiles in the context of food processing technologies, food safety, bioavailability, and the maintenance of the health of consumers.

Author Contributions: R.N. and P.S. made the conception and contributed to writing, J.C. reviewed and edited the chemical parts, E.M. reviewed and revised the manuscript and edited the nutritional parts, P.S. and E.M. finalized the manuscript. All authors have read and agreed to the published version of the manuscript. 
Funding: This research received no external funding.

Institutional Review Board Statement: Not applicable.

Informed Consent Statement: Not applicable.

Data Availability Statement: Data sharing not applicable.

Conflicts of Interest: The authors declare no conflict of interest.

\section{References}

1. Aktas-Akyldiz, E.; Masatcioglu, M.T.; Köksel, H. Effect of extrusion treatment on enzymatic hydrolysis of wheat bran. J. Cereal Sci. 2020, 93, 102941. [CrossRef]

2. Arslan, M.; Rakha, A.; Xiaobo, Z.; Mahmod, M.A. Complimenting gluten free bakery products with dietary fiber: Opportunities and constraints. Trends Food Sci. Technol. 2018, 83, 194-202. [CrossRef]

3. Coda, R.; Katinka, K.; Rizello, C.G. Bran bioprocessing for enhanced functional properties. Curr. Opin. Food Sci. 2015, 1, 50-55. [CrossRef]

4. Tian, S.; Sun, Y. Influencing factor of resistant starch formation and application in cereal products: A review. Int. J. Biol. Macromol. 2018, 149, 424-431. [CrossRef]

5. Kaur, B.; Ariffin, F.; Bhat, R.; Karim, A.A. Progress in starch modification in the last decade. Food Hydrocoll. 2012, 26, 398-404. [CrossRef]

6. Chen, X.; Luo, J.; Fu, L.; Cai, D.; Lu, X.; Liang, Z.; Zhua, J.; Lia, L. Structural, physicochemical, and digestibility properties of starch-soybean peptide complex subjected to heat moisture treatment. Food Chem. 2019, 297, 124957. [CrossRef]

7. Al-Laham, S.H.; Peppelenbosch, M.P.; Roelofsen, H.; Vonk, R.J.; Venema, K. Biological effects of propionic acid in humans, metabolism potential applications and underlying mechanism. Biochim. Biophys. Acta 2010, 1801, 1175-1183. [CrossRef]

8. Tungland, B.C.; Meyer, D. Nondigestible oligo- and polysaccharides (dietary fiber): Their physiology and role in human health and Food. Compr. Rev. Food Sci. Food Saf. 2002, 3, 90-109. [CrossRef]

9. Bhise, S.; Kaur, A. Synergetic effect of polyols and fibres on baking, sensory and textural quality of bread with improved shelf life. Int. J. Curr. Microbiol. Appl. Sci. 2017, 6, 1-12. [CrossRef]

10. Chu, J.; Zhao, H.; Lu, Z.; Lu, F.; Bie, X.; Zhang, C. Improved physicochemical and functional properties of dietary fiber from millet bran fermented by Bacillus natto. Food Chem. 2019, 294, 79-86. [CrossRef]

11. Marco, C.; Rosell, C.M. Breadmaking performance of protein enriched, gluten-free breads. Eur. Food Res. Technol. 2008, 227, 1205-1213. [CrossRef]

12. Zheng, Y.; Li, Y. Physicochemical and functional properties of coconut [Cocos nucifera L] cake dietary fibres: Effects of cellulase hydrolysis, acid treatment and particle size distribution. Food Chem. 2018, 257, 135-142. [CrossRef] [PubMed]

13. Peerjait, P.; Chiwchan, N.; Dehavastin, S. Effects of pretreatment methods on health-related functional properties of high dietary fibre powder from lime residues. Food Chem. 2012, 132, 1891-1898. [CrossRef]

14. Botham, R.L.; Ryden, P.; Robertson, J.A.; Ring, S.G. Structural features of polysaccharides and their influence on fermentation behavior. In Functional Properties of Nondigestible Carbohydrates; Guillon, F., Ed.; INRA: Nantes, France, 1998; pp. 46-49.

15. Slavin, J. Fiber and prebiotics: Mechanisms and health benefits. Nutrients 2013, 5, 1417-1435. [CrossRef] [PubMed]

16. Rowland, I.R.; Rumney, C.J.; Coutts, J.T.; Lievense, L.C. Effect of Bifidobacterium longum and inulin on gut bacterial metabolism and carcinogen-induced aberrant crypt foci in rats. Carcinogenesis 1998, 19, 281-285. [CrossRef]

17. Louis, P.; Hold, G.L.; Flint, H.J. The gut microbiota, bacterial metabolites and colorectal cancer. Nat. Rev. Microbiol. 2014, 12, 661-672. [CrossRef]

18. Brownlee, I.A. The physiological roles of dietary fibre. Food Hydrocoll. 2011, 25, 238-250. [CrossRef]

19. Makarem, N.; Scott, M.; Quatromoni, P.; Jacques, P.; Parekh, N. Trends in dietary carbohydrate consumption from 1991 to 2008 in the Framingham Heart Study Offspring Cohort. Br. J. Nutr. 2014, 111, 2010-2023. [CrossRef]

20. El Khoury, D.; Balfour-Ducharme, S.; Joye, I.J. A review on the gluten-free diet: Technological and nutritional challenges. Nutrients 2018, 10, 1410. [CrossRef]

21. Bonilla, J.C.; Erturk, M.Y.; Kokini, J.L. Understanding the role of gluten subunits [LMW, HMW glutenins and gliadin] in the networking behavior of a weak soft wheat dough and a strong semolina wheat flour dough and the relationship with linear and non-linear rheology. Food Hydrocoll. 2020, 108, 106002. [CrossRef]

22. Kalichevsky, M.T.; Jaroszkiewicz, E.M.; Blanshard, J.M.V. Glass transition of gluten 1: Gluten and gluten-sugar mixtures. Int. J. Biol. Macromol. 1992, 14, 257-266. [CrossRef]

23. Wang, P.; Zhengyu, J.; Xu, X. Physicochemical alterations of wheat gluten proteins upon dough formation and frozen storage. A review from gluten, glutenin and gliadin perspectives. Trends Food Sci. Technol. 2015, 46, 189-198. [CrossRef]

24. Csapó, J.; Csapóné, K.Z. Élelmiszer-Kémia; Mezőgazda Kiadó: Budapest, Hungary, 2003; p. 468.

25. Ojogbo, E.; Ogunsona, E.O.; Mekkonen, T.H. Chemical and physical modifications of starch for renewable polymeric materials. Mater. Today Sustain. 2020, 7-8, 100028. [CrossRef]

26. Ratnayake, W.S.; Jackson, D.S. Chapter 5 Starch Gelatinization. Adv. Food Nutr. Res. 2008, 55, 221-268.

27. Zheng, X.; Li, L.; Wang, X. Molecular characterization of arabinoxylans from hull-less barley milling fractions. Molecules 2011, 16, 2743-2753. [CrossRef] 
28. Farooq, Z.; Boye, J.I. Novel food and industrial applications of pulse flours and fractions. In Pulse Foods: Processing, Quality and Nutraceutical Applications; Academic Press: London, UK, 2011; pp. 283-323.

29. Prückler, M.; Siebenhandl-Ehn, S.; Apprich, S.; Höltinger, S.; Haas, C.; Schmid, E.; Kneifel, W. Wheat bran-based biorefinery. 1: Composition of wheat bran and strategies of functionalization. LWT 2013, 56, 211-221. [CrossRef]

30. Van Craeyveld, V.; Holopainen, U.; Selinheimo, E.; Poutanen, K.; Delcour, J.A.; Courtin, C.M. Extensive dry ball milling of wheat and rye bran leads to in situ production of arabinoxylan oligosaccharides through nanoscale fragmentation. J. Agric. Food Chem. 2009, 57, 8467-8473. [CrossRef] [PubMed]

31. Noort, M.W.J.; van Haaster, D.; Hemery, Y.; Schols, H.A.; Hamer, R.J. The effect of particle size of wheat bran fractions on bread quality-Evidence for fibre-protein interactions. J. Cereal Sci. 2010, 52, 59-64. [CrossRef]

32. Chen, J.S.; Fei, M.J.; Shi, C.L.; Tian, C.J.; Sun, C.L.; Zhang, H.; Ma, Z.; Dong, H.X. Effect of particle size and addition level of wheat bran on quality of dry white Chinese noodles. J. Cereal Sci. 2011, 53, 217-224. [CrossRef]

33. Zhang, D.; Moore, W. Wheat bran particle size effects on bread baking performance and quality. J. Sci. Food Agric. 1999, 79, 805-809. [CrossRef]

34. Coda, R.; Kärki, I.; Nordlund, E.; Heiniö, R.-J.; Poutanen, K.; Katina, K. Influence of particle size on bioprocess induced changes on technological functionality of wheat bran. Food Microbiol. 2014, 37, 69-77. [CrossRef]

35. Bucsella, B.; Takács, Á.; Reding, W.; Schwendener, U.; Kálmán, F.; Tömösközi, S. Rheological and stability aspects of dry and hydrothermally heat treated aleurone-rich wheat milling fraction. Food Chem. 2017, 220, 9-17. [CrossRef] [PubMed]

36. Yan, H.; Zhengbiao, G.U. Morphology of modified starches prepared by different methods. Food Res. Int. 2010, 43, 767-772. [CrossRef]

37. Chi, C.; Li, X.; Lu, P.; Miao, S.; Zhang, Y.; Chen, L. Dry heating and annealing treatment synergistically modulate starch structure and digestibility. Int. J. Biol. Macromol. 2019, 137, 554-561. [CrossRef]

38. Marston, K.; Khouryieh, H.; Aramouni, F. Effect of heat treatment of sorghum flour on the functional properties of gluten-free bread and cake. LWT 2016, 65, 637-644. [CrossRef]

39. Padalino, L.; Caliandro, R.; Chita, G.; Conte, A.; Del Nobile, M.A. Study of drying process on starch structural properties and their effect on semolina pasta sensory quality. Carbohydr. Polym. 2016, 153, 229-235. [CrossRef] [PubMed]

40. Liu, X.-X.; Liu, H.-M.; Fan, L.-Y.; Qin, G.-Y.; Wang, X.-D. Effect of various drying pretreatments on the structural and functional properties of starch isolated from Chinese yam [Dioscorea opposita Thumb.]. Int. J. Biol. Macromol. 2019, 153, 1299-1309. [CrossRef] [PubMed]

41. Colussi, R.; Kringel, D.; Kaur, L.; Zavareze, E.R.; Dias, A.R.G.; Singh, J. Dual modification of potato starch: Effects of heat-moisture and high pressure treatments on starch structure and functionalities. Food Chem. 2020, 318, 126475. [CrossRef] [PubMed]

42. Cahyana, Y.; Wijaya, E.; Halimah, T.S.; Marta, H.; Suryadi, E.; Kurniati, D. The effect of different thermal modifications on slowly digestible starch and physicochemical properties of green banana flour [Musa acuminata colla]. Food Chem. 2019, 274, 274-280. [CrossRef]

43. Huang, T.-T.; Zhou, D.-N.; Jin, Z.-Y.; Xu, X.-M.; Chen, H.-Q. Effect of debranching and heat-moisture treatments on structural characteristics and digestibility of sweet potato starch. Food Chem. 2015, 187, 218-224. [CrossRef]

44. Hung, V.P.; Binh, T.V.; Nhi, Y.H.P.; Phi, L.T.N. Effect of heat-moisture treatment of unpolished red rice on its starch properties and in vitro and in vivo digestibility. Int. J. Biol. Macromol. 2020, 154, 1-8. [CrossRef] [PubMed]

45. Zara, M.; Collins, S.A.R.; Elliston, A.; Wilson, D.R.; Käsper, A.; Waldron, K.W. Characterization of cell wall components of wheat bran following hydrothermal pretreatment and fractionation. Biofuels 2015, 8, 23.

46. Nandeesh, K.; Jyotsana, R.; Rao, G.V. Effect of differently treated wheat bran on rheology, microstructure and quality characteristics of soft dough biscuits. J. Food Process. Preserv. 2011, 35, 179-200. [CrossRef]

47. Nyström, L.; Lampi, M.-A.; Rita, H.; Aura, A.-M.; Oksman-Caldentey, K.-M.; Piironen, V. Effects of processing on availability of total plant sterols, steryl ferulates and steryl glycosides from wheat and rye bran. J. Agric. Food Chem. 2007, 55, 9059-9065. [CrossRef]

48. Aktas-Akyldiz, E.; Matilla, O.; Sozer, N.; Poutanen, K.; Köksel, H.; Nordlund, E. Effect of steam explosion on enzymatic hydrolysis and baking quality of wheat bran. J. Cereal Sci. 2017, 78, 25-32. [CrossRef]

49. Wang, S.; Liu, C.; Wang, S. Drying methods used in starch isolation change properties of C-type chestnut [Castanea mollissima] starches. LWT 2016, 73, 663-669. [CrossRef]

50. Han, Z.; Shi, R.; Sun, D.-W. Effects of novel physical processing techniques on the multi-structures of starch. Trends Food Sci. Technol. 2020, 97, 126-135. [CrossRef]

51. Dupuis, J.H.; Liu, Q.; Yada, R.Y. Methodologies for increasing the resistant starch content of food starches: A review. Compr. Rev. Food Sci. Food Saf. 2014, 13, 1219-1234. [CrossRef]

52. Singh, A.; Raigond, P.; Lal, M.K.; Singh, B.; Thakur, N.; Changan, S.S.; Kumar, D.; Dutt, S. Effect of cooking methods on glycemic index and in vitro bioaccessibility of potato [Solanum tuberosum L.] carbohydrates. LWT 2020, 127, 109363. [CrossRef]

53. Bembem, K.; Sadana, B. Effect of cooking methods on the nutritional composition and antoixidant activity of potato tubers. Int. J. Food Sci. Nutr. 2013, 2, 26-30.

54. Steiner, J.; Franke, K.; Kießling, M.; Fischer, S.; Töpfl, S.; Heinz, V.; Becker, T. Influence of hydrothermal treatment on the structura modification of spent grain specific carbohydrates and the formation of degradation products using model compounds. Carbohydr. Polym. 2018, 184, 315-322. [CrossRef] 
55. Pei-Ling, L.; Xiao-Song, H.; Qun, S. Effect of high hydrostatic pressure on starches: A review. Starke 2010, 62, 615-628. [CrossRef]

56. Zavareze, R.E.; Pinto, Z.V.; Klein, B.; El Halal, M.L.S.; Elias, C.M.; Prentice-Hernández, C.; Dias, G.R.A. Development of oxidised and heat-moisture treated potato starch film. Food Chem. 2012, 132, 344-350. [CrossRef]

57. Liu, H.; Fan, H.; Cao, R.; Blanchard, C.; Wang, M. Physicochemical properties and in vitro digestibility of sorghum starch altered by high hydrostatic pressure. Int. J. Biol. Macromol. 2016, 92, 753-760. [CrossRef]

58. Sun, B.; Rahman, M.M.; Tar'an, B.; Yu, P. Determine effect of pressure heating on carbohydrate related molecular structures in association with carbohydrate metabolic profiles of cool-climate chickpeas using globar spectroscopy. Spectrochim. Acta A 2018, 201, 8-18. [CrossRef]

59. Santala, O.; Kiran, A.; Sozer, N.; Poutanen, K.; Nordlund, E. Enzymatic modification and particle size reduction of wheat bran improves the mechanical properties and structure of bran-enriched expanded extrudates. J. Cereal Sci. 2014, 60, 448-456. [CrossRef]

60. Yan, X.; Wu, Z.-Z.; Li, Y.-L.; Yin, F.; Ren, K.-X.; Tao, H. The combined effects of extrusion and heat-moisture treatment on the physicochemical properties and digestibility of corn starch. Int. J. Biol. Macromol. 2019, 134, 1109-1112. [CrossRef]

61. Liu, Y.; Chen, J.; Wu, J.; Luo, S.; Chen, R.; Liu, C.; Gilbert, R.G. Modification of retrogradation property of rice starch by improved extrusion cooking technology. Carbohydr. Polym. 2019, 213, 192-198. [CrossRef]

62. Yousefi, A.R.; Razavi, S.M.A. Steady shear flow behavior and thixotropy of wheat starch gel: Impact of chemical modification, concentration and saliva addition. J. Food Process Eng. 2016, 39, 31-43. [CrossRef]

63. Fang, F.; Martinez, M.M.; Campanella, O.H.; Hamaker, B.R. Long-term low shear-induced highly viscous waxy potato starch gel formed through intermolecular double helices. Carbohydr. Polym. 2020, 232, 115815. [CrossRef]

64. Bailoni, L.; Mantovani, R.; Pagnin, G.; Schiavon, S. Effects of physical treatments on the resistant starch content and in vitro organic matter digestibility of different cereals in horses. Livest. Sci. 2006, 100, 14-17. [CrossRef]

65. Al-Loman, A.; Ju, L.-K. Enzyme-based processing of soybean carbohydrate: Recent developments and future prospects. Enzyme Microb. Technol. 2017, 106, 35-47. [CrossRef]

66. Misra, N.N.; Yadav, B.; Roopesh, M.S.; Jo, C. Cold plasma for effective fungal and mycotoxin control in foods: Mechanisms, inactivation effects, and applications. Compr. Rev. Food Sci. Food Saf. 2019, 18, 106-120. [CrossRef]

67. Zhou, Y.; Yan, Y.; Shi, M.; Liu, Y. Effect of an atmospheric pressure plasma jet on the structure and physicochemical properties of waxy and normal maize starch. Polymers 2019, 11, 8. [CrossRef]

68. Thirumdas, R.; Deshmuk, R.R.; Annapure, U.S. Effect of low temperature plasma on the functional properties of basmati rice flour. J. Food Sci. Terchnol. 2016, 53, 2742-2751. [CrossRef]

69. Thirumdas, R.; Trimukhe, A.; Deshmuk, R.R.; Annapure, U.S. Functional and rheological properties of cold plasma treated rice starch. Carbohydr. Polym. 2017, 157, 1723-1731. [CrossRef]

70. Okyere, A.Y.; Bertoft, E.; Annor, G.A. Modification of cereal and tuber waxy starches with radio frequency cold plasma and its effects on waxy starch properties. Carbohydr. Polym. 2019, 223, 115075. [CrossRef]

71. Banura, S.; Thirumdas, R.; Kaur, A.; Deshmuk, R.R.; Annapure, U.S. Modification of starch using low pressure radio frequency air plasma. LWT 2017, 89, 719-724. [CrossRef]

72. Held, S.; Tyl, C.E.; Annor, G.A. Effect of radio frequency cold plasma treatment on intermediate wheatgrass [Thinopyrum intermedium] flour and dough properties in comparison to hard and soft wheat [Triticum aestivum L.]. J. Food Qual. 2019, 2019, 1085172. [CrossRef]

73. Nguyễn, L.T.; Trinh, S.K. Structural, functional properties and in vitro digestibility of maize starch under heat-moisture and atmospheric cold plasma treatments. Vietnam J. Sci. Technol. 2018, 56, 751-760. [CrossRef]

74. Scholtz, V.; Sera, B.; Khun, J.; Sery, M. Effects of nonthermal plasma on wheat grains and products. J. Food Qual. 2019, 1, 1-10. [CrossRef]

75. Bahrami, N.; Bayliss, D.; Chope, G.; Penson, S.; Perehinec, T.; Fisk, I.D. Cold plasma: A new technology to modify wheat flour functionality. Food Chem. 2016, 202, 247-253. [CrossRef] [PubMed]

76. Polesi, L.F.; Sarmento, S.B.S.; de Moraes, J.; Franco, C.M.L.; Carniatti-Brazaca, G.S. Physicochemical and structural characteristics of rice starch modified by irradiation. Food Chem. 2016, 191, 59-66. [CrossRef] [PubMed]

77. Chung, K.-H.; Othman, Z.; Lee, J.-S. Gamma irradiation of corn starches with different amylose-to-amylopectin ratio. J. Food Sci Technol. 2015, 52, 6218-6229. [CrossRef]

78. Atrous, H.; Benbettaieb, N.; Chouaibi, M.; Attia, H.; Ghorbel, D. Changes in wheat and potato starches induced by gamma irradiation: A comparative macro and microscopic study. Int. J. Food Prop. 2015, 20, 1532-1546. [CrossRef]

79. Brașoveanu, M.; Nemtanu, M.-R. Aspects on starches modified by ionizing radiation processing. In Applications of Modified Starches; Huicochea, E.F., Villalobos, R.R., Eds.; IntechOpen: London, UK, 2018. [CrossRef]

80. Lewandowicz, G.; Jankowski, T.; Fornal, J. Effect of microwave radiation on physico-chemical properties and structure of cereal starches. Carbohdydr. Polym. 2000, 42, 193-199. [CrossRef]

81. Shen, H.; Fan, D.; Huang, L.; Gao, Y.; Lian, H.; Zhao, J.; Zhang, H. Effects of microwaves on molecular arrangements in potato starch. RSC Adv. 2017, 7, 14348-14353. [CrossRef]

82. Román, L.; Martínez, M.M.; Rosell, C.M.; Gómez, M. Effect of microwave treatment on physicochemical properties of maize flour. Food Bioprocess Technol. 2015, 8, 1330-1335. [CrossRef] 
83. Kurdziel, M.; Labanowska, M.; Pietrzyk, S.; Sobolewska-Zielínska, J.; Michalec, M. Changes in the physicochemical properties of barley and oat starches upon the use of environmentally friendly oxidation methods. Carbohydr. Polym. 2019, 210, 339-349. [CrossRef]

84. Nawaz, H.; Waheed, R.; Nawaz, M.; Shahwar, D. Physical and chemical modifications in starch structure and reactivity. In Chemical Properties of Starch; Emeje, M., Ed.; IntechOpen Ltd.: London, UK, 2020. [CrossRef]

85. Bajer, D.; Kaczmarek, H.; Bajer, K. The structure and properties of different types of starch exposed to UV radiation: A comparative study. Carbohydr. Polym. 2013, 98, 477-482. [CrossRef]

86. Vatanasuchart, N.; Naivikul, O.; Charoenrein, S.; Sriroth, K. Molecular properties of cassava starch modified with different UV irradiations to enhance baking expansion. Carbohydr. Polym. 2005, 61, 80-87. [CrossRef]

87. Franco, C.M.L.; Ogawa, C.; Rabachini, T.; Rocha, T.S.; Cereda, M.P.; Jane, J.-L. Effect of lactic acid and UV irradiation on the cassava and corn starches. Braz. Arch. Biol. Technol. 2010, 53, 443-454. [CrossRef]

88. Peyron, S.; Abecassis, J.; Autran, J.-C.; Rouau, X. Influence of UV exposure on phenolic acid content, mechanical properties of bran, and milling behavior of durum wheat [Triticum Durum Desf.]. Cereal Chem. 2002, 79, 726-731. [CrossRef]

89. Reynolds, A.N.; Akerman, A.P.; Mann, J. Dietary fibre and whole grains in diabetes management: Systematic review and meta-analyses. PLoS Med. 2020, 17, e1003053. [CrossRef]

90. Ocvirk, S.; Wilson, A.S.; Appolonia, C.N.; Thomas, T.K.; O'Keefe, S.J.D. Fiber, fat, and colorectal cancer: New insight into modifiable dietary risk factors. Curr. Gastroenterol. Rep. 2019, 21, 62. [CrossRef] 